\title{
$347 \cdot 633$
}

\section{O Antigo e o Nôvo Estatuto da Adoção*.}

\author{
R. Limongi França \\ Docente da Faculdade de Direito da Univer- \\ sidade de São Paulo.
}

I. DO CONCEITO DE ADOÇÃo. - 1. A lição dos mestres. 2. Nossa proposta de conceito de adoção. II. HISTórico E DIREITO COMPARAD0. - 1. Breve indicação histórica. 2. Direito Comparado. 3. O Direito Positivo Anterior. A) $\mathrm{O}$ sistema anterior ao Código. B) O sistema do Código. III. o DIREITo Positivo AtUAL. - 1. A Lei 3.133 de 1957. 2. Sujeito Ativo da Adoção. 3. Sujeito Passivo. 4. Requisitos. 5. Efeitos. 6. Extinção. IV. CONCLUSÃo SôBRE O VERDADEIRO CARÁTER DA NOVA ADOÇĀO.

\section{Do conceito de adoção.}

1 A lição dos mestres. Adoção vem do latim, adoptio onis (V. Santos Saraiva, Novissimo Dicionário LatinoPortuguês, Waldemar Cesar da Silverra, Dicionário de Direito Romano, v. I, S. Paulo, 1957). Em italiano deu adozione; em espanhol, adopción; em francês, adoption; em inglês, adoption, com acento no primeiro "o"; em alemão, adoption, com "A" maiúsculo e pronunciando-se o " $t$ " como tal. Na mesma língua germânica, diz-se também Einkindung (V Antonio Chaves, Adoção e Legitimação adotiva, p. 15, S. Paulo, 1965).

* Dedicamos êste estudo ao Prof. ANtonio Chaves, pioneiro nos avanços científicos, entre nós, do estudo da matéria. 
O sentido do vocábulo, nesses diversos idiomas, quando não idêntico, é análogo e quase coincidente.

Bevilaqua, no Código Civil Comentado, v. II, p. 346, $7 .^{\mathrm{a}}$ ed., 1945, ensina que a adoção "é o ato civil, pelo qual alguém aceita um estranho na qualidade de filho"

Embora inexato, porque o adotado pode não ser um estranho, êste conceito tem sido repetido por alguns civilistas, inclusive por Itabaiana DE Oliveira, no Tratado de Direito das Sucessões, v. I, p. 192 e segs., 202 e segs., $4 .^{\mathrm{a}}$ ed., 1952.

Carvalho Santos (Código Civil Interpretado), seguindo a Deмоlomве aproxima-se mais da verdade, considerando-a o "ato jurídico que estabelece entre duas pessoas relações civis de paternidade e de filiação"

De quantos examinamos, o conceito mais completo é o do eminente especialista da matéria, o Prof. Antonio Chaves, que assim o articula: "Adoção é o ato sinalagmático e solene, pelo qual, obedecidos os requisitos fixados em lei, alguém estabelece, geralmente com um estranho, um vínculo fictício de paternidade e filiação legitima, de efeitos limitados, e sem total desligamento do adotando, de sua família de sangue" (Adoção e Legitimação Adotiva, p. 17, S. Paulo, 1965).

2. Nossa proposta de conceito de adoção. De nossa parte, atendendo às transformações pelas quais passou o instituto, à face da realidade dos problemas sociais do menor, pensamos que, mesmo em se tratando de um conceito, cujo conteúdo por natureza deve ser sintético, essa nova faceta da adoção não pode ser olvidada.

Isso, aliás, não escapou a Crovis embora tenha escrito no regime anterior ao da Lei 3.133: "o que é preciso salientar é a ação benéfica e social e individualmente falando, que a adoção pode exercer na sua fase atual (1916-1944, data do falecimento do mestre) . Chamando, para o aconchego da familia e para as doçuras do bem 
estar, filhos privados de arrimo ou de meios idôneos" Com isso, a família adotiva "aproveita e dirige capacidades, que, de outro modo, corriam o risco de se perder" (Cod. Com. II, 346).

Daí o seguinte conceito de adoção, que propomos: é um instituto de proteção à personalidade, em que essa proteção se leva a efeito através do estabelecimento, entre duas pessoas - o adotante e o protegido adotado - de um vínculo civil de paternidade (ou maternidade) e de filiação.

\section{Histórico e Direito Comparado.}

1. Breve indicação histórica. A adoção é um instituto antiquíssimo, pois no Código de Hamurabi, que antecede de um milênio e meio a Lei das XII táboas, já se encontra um número surpreendente de dispositivos a respeito da matéria. (Arts. 185-193, V. ed. Pietro Bonfante, Le Leggi di Hammurabi, Re di Babilonia, Milão, 1903; cf. Hersilio de Souza, O Código de Hamurabi in "Revista Acadêmica da Faculdade de Direito do Recife", p. 287 e segs., 1923).

Com efeito, aí está disposto, como princípio, no art. 183 que - "Si alguem dá seu nome a uma criança e a cria como filho, êste adotado não poderá mais ser reclamado" Além disso, muitas disposições se encontram, a revelar considerável amadurecimento jurídico, a respeito da rescisão da adoção (arts. 186, 189, 190, etc.), das obrigaçõ€s recíprocas entre adotante e adotado (arts. 189, 191, 192, 193), bem assim do caso particular da adoção do exposto (arts. 187, 193).

Em Roma apresentou grande desenvolvimento, tendo influido mesmo na sua propria vida política, através de adoções de chefes militares e líderes politicos.

Em Modestro (D. 1, VII, pr.) encontramos a lição de que os filhos não se fazem apenas pela natureza, senão 
também pela adoção - filios familias non solum natura, verum et adoptiones faciunt.

A adocão, no Direito Justinianeu, é nome geral, nomen est quidem generale, e se divide em duas espécies: a adoção, stricto sensu, e a adrogação. A adoção se refere aos filhos-familias, aquêles que se encontram sob o poder do chefe da gens. A adrogação diz respeito aos que são sui juris (loc. cit.).

Nas Institutas, que dedicam todo um título à matéria (I, XI), se deparam preceitos e observações de particular sabedoria, como p. ex., a de que o mais moço não pode adotar o mais velho, pois, uma vez que a adoção imita a natureza, seria monstruoso que o filho tivesse mais idade que o pai -- pro monstro est, ut maior sit filius quam pater.

2. Direito Comparado. Quanto ao Mundo Jurídico Moderno, pode dizer-se que a adoção é um instituto de direito das gentes, pois, salvo raríssimas exceções, se vê nos quatro cantos do orbe.

$\mathrm{Na}$ Europa Latina, encontra-se no Código de Napoleão, art. 343 e segs., no Código Italiano de 1865, art. 202 e segs., etc.. Na Europa Germânica, acha-se no Código Austriaco, de 1811, art. 179 e segs. e Lei de 25 de outubro de 1941; no Código Alemão, art. 1741 e segs.

Na América Latina, citamos como exemplo o Código Peruano, arts. 326-347.

No próprio Oriente, a adoção se depara no Código Civil Chinês, de 1931, art. 1.072 e segs., bem assim no Código Japonês, onde apresenta minucioso desenvolvimento: arts. 836 a 876 , portanto, mais de quarenta dispositivos.

A Rússia Soviética também não a desconheceu, consagrando-a em seu Código da Família, arts. 57 a 67.

Três exceções importantes devem ser assinaladas.

A do Código Holandês (v. edição de P H. HaAnebrink, Bruxelas-Paris, 1921), a do Argentino e a do Português, de 1867. 
Quanto ao Sistema Neerlandês, não encontramos elementos para falar do seu estágio atual.

No referente ao Argentino, porém, a lacuna foi corrigida, graças a dois projetos, um de Castillo, de 1933, e outro do Presidente Opitiz, de 1938, os quais, com as modificações de costume e, particularmente, "siguiendo mas cerca al Codigo de Brasil, arts. 368-378" (V JosÉ Arias, Derecho de Família, p. 345, Buenos Aires, 1952). se transformaram em lei, promulgada em 23 de setembro de 1948.

No que tange ao Direito Luso, o seu novo e belíssimo Código, de $1 .^{\circ}$ de junho de 1967, consagra o instituto, nos artigos 1.973 a 2.002, bipartindo-o em adoção plena e adoção restrita.

3. O Direito Positivo Anterior. A) O sistema anterior ao Código. Como não poderia deixar de ser, quando menos em razão do papel supletivo do Direito Romano e do Canônico, o nosso Direito Anterior não desconhecia a adoção.

Não há, porém, nas Ordenações de D. Felipe (1603-1917) um capítulo ou título dedicado à matéria, senão referências fragmentárias, como a do L. III, tít. $9, \S 2 .^{\circ}$, de que "nem poderá ser citado o pai adoptivo pelo adoptado enquanto durar entre êles a afinidade" No mesmo livro outras alusões se deparam no título $59, \S 111$ e no título 85 , $\S 2 .^{\circ} \quad$ O mesmo se dá com o Livro II, tít. $35, \S 12$ e tít. 56, pr.. Longe, porém, de se pensar em um sistema em relação ao assunto.

Proclamada a Independência, o art. $2 .^{\circ}$ da Lei de 22 de setembro de 1828 tocou no tema.

Mas na própria Consolidação Teixeira de Freitas, o que encontramos de relevante é o art. 217, onde se diz que -.. "aos Juizes de primeira instância compete conceder cartas de legitimação aos filhos sacrilegos, adulterinos e incestuosos, e confirmar as adoções." 
A matéria ressurge, posteriormente, no estatuto do casamento civil, Dec. 181, de 24 de janeiro de 1890 , art. $7 .^{\circ}$, $\S 1 .^{\circ}$, e, em 1899, Carlos de Carvalho encontrou já elementos suficientes para, em a "Nova Consolidação", disciplinála nos arts. 1.635 a 1.640 .

Trata-se, porém, de instituto muito discutido, olhado de soslaio pelos patriarcas e coronéis de uma estrutura paradoxal e decadente.

Na Argentina, SArsfield, ao suprimi-lo, "negava que, em seu tempo, estivesse nos costumes e que trouxesse algum bem social" (JasÉ ARIAS, Op. cit., p. 344).

Entre nós, como em Portugal, o que se temia é que, através da adoção, adulterinos e outros espúrios se introduzissem na conspícua família legitima. CLóvis, porém, que sentiu o problema na própria carne (V. a sua biografia, Clóvis Bevilaqua, de autoria do Dr. Rarmundo DE Menezes), não trepidou, em afirmar, com a sua franciscana serenidade: "Se sòmente para êsse fim servisse a adoção, já seria de alta valia o seu préstimo" (Cod. Com., II, p. 346, 7.a ed., 1945).

Assim, em 1916, o Código, cujo projeto foi de sua autoria, regulou a matéria nos arts. 368 a 378 .

B) O Sistema do Código. Para não haver dúvidas, alinharemos nossas breves considerações sôbre o sistema do Código, baseado no texto oficial, de 1919, "Lei $\mathrm{n} .^{\circ} 3.071$, de $1 .^{\circ}$ de janeiro de 1916 , com as correçốes ordenadas pela Lei n. 3.725 , de 15 de janeiro de 1919 "

Não levaremos a efeito - nem é êste o lugar azado - uma análise vertical de todos os seus dispositivos.

Limitar-nos-emos, e de maneira suscinta, a considerar três dos seus artigos: o 368 , o 369 e o 377

O primeiro reza que "Só os maiores de cincoenta anos, sem prole legitima ou legitimada, podem adotar" Conforme o preceito seguinte, "o adotante há de ser, pelo menos, dezoito anos mais velho que o adotado". 
E, finalmente, o art. 377, princípio, dispõe que os efeitos da adoção se produzem "ainda que sobrevenham filhos ao adotante".

Bastam êstes textos para mostrar que o regime do Código é de caráter rígido e fechado, de modo a estabelecer mesmo verdadeiros entraves para a adoção, de onde a reduzida constância da sua prática.

Primeiro, a limitação apenas às pessoas casadas, quando a solidão de pessoas solteiras pode perfeitamente ir ao encontro das necessidades de menores desamparados, numa comunicação recíproca dos melhores afetos, em benefício espiritual e material, tanto do adotante como do adotado.

Segundo, a concessão da legitimatio para adotar só aos maiores de cinqüenta anos, limite excessivamente restrito. que prejudica o número de adoções.

Terceiro, a inexistência de prole legitima ou legitimada, fruto da ignorância do tempo, a respeito do salutar ambiente das familias numerosas.

Quarto, a desnecessária diferença de dezoito anos entre o adotante e o adotado.

E quinto - o grande espantalho - o direito sucessório - oriundo do art. 377, ainda que sobreviessem filhos ao adotante.

\section{O Direito Positivo Atual.}

1. A Lei 3.133, de 195\%. Apesar de todos os seus defeitos - alguns imperdoáveis — a Lei 3.133 , de 8 de maio de 1957, trouxe uma série de modificações ao regime do Código, de forma a fazer da adoção um instituto, não só exequível dentro de uma perspectiva normal de vida, como ainda destinado a atender, com a largueza de vistas que o informou, a problemas da mais alta relevância social, especialmente o da proteção da pessoa do menor.

Por fôrça de suas disposições, foram modificados os artigos 368, 369, 374 e 377 do Código. 
Além disso. conforme o seu art. $2 .^{\circ}$, acrescentou-se ao sistema um elemento importante, a saber, um preceito relativo ao direito ao nome do adotado.

2. Sujeito Ativo da Adoção. Conforme o estatuto do Código, como foi visto, só podiam adotar as pessoas casadas, de mais de cinqüenta anos, e sem prole legítima ou legitimada.

A Lei 3.133 realmente alargou as possibilidades da adoção, atribuindo a capacidade (legitimatio) para adotar aos maiores de trinta anos.

Por outro lado, introduziu no art. 368 o seguinte parágrafo único: "Ninguém pode adotar, sendo casado, senão decorridos 5 (cinco) anos após o casamento".

A contrário, conclui-se, para logo, que não sendo a pess̄oa casada, êsse requisito não tem razão de ser.

Mas o efetivamente importante não é tanto a dispensa dêsse requisito, senão a atribuição, também às pessoas solteiras, viuvas ou desquitadas, da capacidade de serem sujeito ativo da adoção.

O novo estatuto mantém a disposição do art. 371, referente ao tutor e ao curador.

Não há razão natural para impedi-los de serem adotantes. Mas é necessário e justo que a lei acautele os interêsses de menores e interditos, exigindo, para êsse fim, que, prèviamente, tutor e curador prestem contas de sua administração e saldem o seu alcance.

0 adotante, pelo novo estatuto, ao invés de dezoito, há de ser dezesseis anos mais velho que o adotado (art. 369), o que se prova fàcilmente pelas respectivas certidões de idade. Quando as não haja, podem ser feitas por justificação judicial, admitindo-se as provas de direito, sob o alto critério do Magistrado, ouvido sempre o Ministério Público. 
3. Sujeito Passivo da Adoção. Clóvis, em seu conceito de adoção, refere o sujeito passivo como sendo uma pessoa estranha.

o defeito é da definição $e^{\prime}$ não do pensamento do mestre, que a estende também a pessoas não estranhas, inclusive filhos ilegitimos ( $O p$. et loc. cits.).

Essa orientação já vem do Direito Romano. Nas Institutas, I, XI, 7, encontramos referência expressa ao filho natural; e, no mesmo lugar, $\S 9$ está dito assim: si quis . NOM EXTRANEUm adoptaverit, potest eundem alii in adoptionem dare.

No mesmo sentido, o ensinamento do Prof. Antonio Chaves (Op. cit., p. 16-18).

Quanto a outros aspectos do sujeito passivo da adoção, a lei é inespecífica. Entretanto, são dedutíveis, a contrário, dos arts. 369,371 e 373.

Assim, no que lhe concerne, quanto à idade, há de ser, pelo menos, dezesseis anos mais novo que o adotante.

Por outro lado, nada impede que seja: capaz ou incapaz; maior ou menor (art. 373); pupilo ou interdito.

3. Requisitos. Já vimos, implìcitamente, em matéria de requisitos, quanto respeita ao estado, quer do adotante, quer do adotado (Sôbre a noção de estado e seus vários aspectos, v. nosso Manual, v. I, pgs. 129 e segs., ed. 1966).

Há-os outros, porém.

Assim, é ainda necessário:

A) o consentimento do adotado;

B) que a adoção seja feita por uma só pessoa, salvo se se tratar de marido e mulher (art. 370);

C) que se obedeça a uma forma solene no caso, a escritura pública (art. 375);

D) que não haja termo ou condição (Manual, v. I, pgs. 225-233).

Algumas considerações, por indispensáveis, apenas quanto ao consentimento. 
Se o adotado é maior e capaz, inexiste problema: êle dará ou não o seu consentimento. Não anuindo, não há cogitar de adoção (Cod. art. 82, interpretado).

Se, porém, menor ou incapaz algumas questões se colocam. Destas, duas mais importantes: a) quem deve representar o menor ou incapaz; b) se a manifestação, por parte do representante, é definitiva.

a) O Código atribuía, na espécie, a representação, à "pessoa, debaixo de cuja guarda estiver o adotando, menor ou interdito"

Ora, a simples guarda pode ser precária e não estar acometida, transitòriamente, a pessoas mais diretamente ligadas à responsabilidade pelo menor.

Assim o texto da Lei 3.133 constitui mais um testemunho de que a adoção evoluíu no sentido de instituto de proteçầo ḋ personalidade do adotado. A responsabilidade pela manifestação da vontade é, no caso, reforçada, deferindo-a a lei ao representante legal.

b) Essa declaração de vontade, porém, não é definitiva.

O menor ou interdito, tanto no regime do Código, como da Lei 3.133 (art. 373), pode desligar-se da adoção no ano imediato ao em que cessar a interdição, ou menoridade.

Un derradeiro aspecto fundamental do problema dos requisitos: o de se poder ou não adotar mais de uma pessoa

A resposta é afirmativa. Por três razões: a) porque a lei näo o proibe; b) porque é da conveniência do próprio adotado, especialmente se menor, o ser criado em meio a uma fámília numerosa; e c) porque a adoção, evoluindo, de instituto de direito de família, para de proteçâo $\dot{a}$ personalidade deve alcançar o maior número de pessoas.

5. Efeitos da adoção. Os efeitos da adoção, fundamentalmente, são quatro, a saber: A) transmite o patrio poder, do genitor natural, ao adotivo; B) dá azo ao enta- 
bulamento de relações de parentesco, quanto à família do adotante; C) cria direitos à sucessão causa mortis; e, D) atribui ao adotado o direito ao nome do adotante.

Examinemos, ràpidamente embora, cada um dêsses efeitos fundamentais.

A) Transmite o patrio poder, do genitor natural, ao adotivo (art. 378), dando ensejo, dêsse modo, ao aparecimento daquilo que Savatier (Cours, vol. I, 2. ${ }^{a}$ ed.. 1947) e Marty e Raignaud (Droit Civil, vol. I, 1961) denominam familia adotiva. Não obstante, salvo o que concerne ao patrio poder, o adotado continua jungido às mesmas obrigações e desfrutando dos mesmos direitos concernentes à família de origem.

B) Dá azo ao entabulamento de relações de parentesco, quanto à família do adotante. O Código diz que êsse parentesco se limita entre o adotante e o adotado (art. 376). Mas não é exatamente assim, porque se estende aos impedimentos matrimoniais, previstos no art. 183, $\mathrm{n}^{\mathrm{o}} \mathrm{s}$. III e V.

Dessa forma, não podem casar, em virtude de parentesco adotivo: a) o adotante com o cônjuge do adotado; b) o adotado com o cônjuge do adotante $\left(183, n .^{\circ}\right.$ III); c) o adotado com o filho superveniente ao pai adotivo; d) o adotado com o filho superveniente à mãe adotiva.

C) Cria direitos à sucessão causa mortis. No sistema do Código êsse efeito era inapelável. Apenas, se houvesse filhos supervenientes, ao adotivo tocava sòmente o equivalente à metade do quinhão dos filhos de sangue (art. 1.605, $\left.\S 2 .^{\circ}\right)$.

O estatuto em vigor, entretanto, dispõe que, quando o adotante tiver filhos legítimos, legitimados ou reconhecidos, a relação de adoção não envolve a de sucessão hereditária.

Esta disposição afeta ainda o art. 1.609, § único, do Código, que erigia o adotante em herdeiro do adotado, em 
não existindo os pais de sangue, quando da abertura da sucessã̃o (art. 1.572).

D) Atribui ao adotado o direito ao nome do adotante. No Direito Romano e nos Códigos Modernos essa era a regra (V. Limongi França, Do Nome Civil das Pessoas Naturais, p. 235-237, 2. ${ }^{\mathrm{a}}$ ed., 1964).

Entre nós, o Código silenciava a respeito, mas a Lei 3.133 , art. $2^{\circ}$, determina que no ato da adoção se declarem os apelidos do adotado, que poderão ser: a) os dos pais de sangue, acrescidos dos do adotivo; b) apenas os dos pais de sangue; e, c) apenas os do adotivo.

Fôrça é convir, porém, que, não obstante a oportunidade do preceito, quanto ao seu conteúdo, êle aberra dos princípios fundamentais que regem a formação do nome.

O Direito ao Nome é a principal expressão do direito à identidade pessoal e familiar (V. Adriano De Cupis, Il Diritto all'Identitá Personale, Milano, 1949; Do Nome Civil das Pessoas Naturais, p. 136-192, 2. ${ }^{\text {a }}$ ed.). Nos termos em que a lei disciplina a matéria é possivel que irmãos adotivos tenham nome completamente diferentes o que é a antítese da finalidade do direito à designação personativa.

6. Extinção da Adoção. A adoção, conforme as circunstâncias, e, de acôrdo com determinados requisitos, se extingue de três modos: A) por vontade do adotado; B) por vontade de ambas as partes (adotante e adotado); C) contra a vontade do adotado; e D) contra a vontade do adotante.

A) Extinção, por vontade do adotado. Trata-se do caso do menor ou do interdito, cuja vontade, quando da adoção, se manifesta através do representante legal (art. 372, com a redação da Lei 3.133).

Cessada a interdição ou a menoridade, dentro do ano imediato, um e outro poderão desligar-se do vínculo adotivo (Código, art. 373). 
B) Extinção, por vontade de ambas as partes. O desfazimento da adoção por anuência do adotante e adotado já estava previsto no art. 374, n. $^{\circ}$ I do Código e a Lei 3.133 o manteve, nos mesmos termos.

Note-se, porém, que a adoção, tendo sido entabulada por escritura pública (art. 375), deve resilir-se pela mesma forma (art. 1.093).

C) Extinção, contra a vontade do adotado. O adotado pode ser destituído da condição de filho adotivo.

o Código (art. 374, II) estabelecia que isto tinha lugar quando o adotado cometesse ingratidão contra o adotante.

A Lei 3.133 foi bem mais longe: dispõe que tal se dá "nos casos em que é admitida a deserdação".

Ora, a deserdação se dá, fundamentalmente, de duas maneiras: a) por vontade do adotante; e b) independentemente da vontade do adotante. $O$ primeiro caso denominamos deserdação pròpriamente dita; o segundo, exclusão de herdeiro.

a) Incluem-se na primeira hipótese, além dos casos de exclusão (art. 1.595, 1.744), os seguintes: 1. ofensas físicas; 2 . injúria grave; 3 . desonestidade da filha que vive na casa paterna; 4 . relações ilícitas com a madrasta ou o padrasto (no caso, também com a mãe ou pai adotivo); 5. desamparo; do adotante em caso de alienação mental ou grave enfermidade.

Nestas espécies, a extinção da adoção só pode ser ordenada pelo adotante em escritura pública ou no próprio testamento, juntamente com a deserdação mesma, se for caso $(1.092,1.742)$.

b) Por outro lado, são casos de exclusão (que também o podem ser de deserdação) os seguintes: 1. o ter sido o adotado autor ou cumplice em crime de homicídio voluntário, ou tentativa dêste contra o adotante; 2 . o haver o adotado caluniado em juízo o adotante; 3 . a prática de crime, por parte do adotado, contra a honra do adotante; 
4. a inibição, por parte do adotado, em relação ao adotante, com violência ou fraude, quanto à livre disposição dos bens dêste, em ato de última vontade (art. 1.595).

Nestas hipóteses, a extinção da adoção pode ser promovida, não só por herdeiro interessado na sucessão (art. 1.596), mas ainda, em se tratando apenas da adoção, por pessoa da família, que tenha legitimo interêsse moral.

D) Extinção, contra a vontade do adotante. E reverso da medalha do caso anterior.

$\mathrm{O}$ assento da matéria é o art. 1.745 do Código.

Mutatis mudandis, adotado, ou terceiro interessado, se se trata de causa de deserdação ou de exclusão, pode promover o desfazimento do vínculo adotivo.

IV. Conclusão sôbre o verdadeiro caráter da nova adoção.

A conclusão sôbre o verdadeiro caráter da nova adoção deflui com facilidade do simples confronto, já feito ao longo destas linhas, entre o texto original do Código e as derrogações introduzidas pela Lei 3.133.

As modificações quanto ao sujeito ativo e o passivo, alargando as possibilidades de adotar; quanto aos efeitos, de modo a evitar o espantalho da sucessão causa mortis. compulsória e indiscriminada; e quanto à extinção, oferecendo também ao adotado, meios mais amplos de se libertar de uma adoção impossivivel, além de muitos outros aspectos que se poderiam esmiuçar, mostram, em suma. duas coisas:

primeiro, o desejo do legislador de fazer da adoção um modo mais viável de atender particularmente ao problema de pessoas desamparadas, especialmente menores (veja-se que a idade do adotante passou de cinqüenta para trinta anos, etc.);

segundo, a propiciação de uma condição melhor para o adotado, proporcionando a êste ou a terceiro (art. 374, 
II, com a redação da Lei 3.133$)$ possibilidade, de extinguir a adoção, contra a vontade do próprio adotante.

Não há dúvida de que, criando vínculo civil de filiação e paternidade a adoção ainda participa de elementos do Direito de Família e a ela se pode referir, conforme Savatier (Cours de Droit Civil, I, 2. ${ }^{a}$ ed., 1947) e Marty e Raignaul (Droit Civil, vol. I, 1961) como à familia adotiva.

Mas, sobretudo, o que interessa de novo é que, além e acima dêsses aspectos tradicionais, que vem desde o Direito Babilônico e o Romano, novos elementos surgiram, dentro de uma outra visão da matéria e segundo uma nova perspectiva, de forma a poder considerar-se, atualmente, de modo especial, como um instituto de proteçẫo à personalidade do adotado. 